\title{
Application of Artificial Intelligence in Autonomous English Learning Among College Students
}

\author{
https://doi.org/10.3991/ijet.v14i06.10157 \\ Bing Han \\ Hebi Polytechnic, Hebi, China \\ zibing_water@163.com
}

\begin{abstract}
To improve the English proficiency of college students, this paper attempts to promote autonomous English learning among these students using artificial intelligence technology. Specifically, the principles, features and application fields of artificial intelligence were introduced in details, and the requirements, structure, database and processes of autonomous English learning systems were discussed at length. On this basis, the backpropagation (BP) neural network, a typical artificial intelligence technique, was selected to design the modules of the autonomous English learning system for college students. The proposed system was then implemented in integrated open environment of Visual Studio, the architecture of the browser/server system and the SQL Server database on the Windows platform. The results show that the proposed system provides college students with intelligent and open self-evaluation tests and effective learning feedbacks. The research findings shed new light on improving the English learning of college students and reliving the pressure on college English teachers.
\end{abstract}

Keywords-Artificial Intelligence; autonomous learning; college students; Backpropagation (BP) neural network

\section{$1 \quad$ Introduction}

In the information era, knowledge dissemination and teaching methods and teaching environment are undergoing unprecedented changes. Traditional teaching methods are no longer unable to meet the needs of the contemporary society for cultivation of composite talents, especially in the field of English teaching [1]. English teaching reform has been carried out for many years because traditional examination-oriented education model is not quite effective in English language teaching. At present, college English teaching produces very little effect in improving college students' English skills. Many college students' English skills are still at the senior high school level or even worse. So, the traditional college English teaching model needs to be reformed by integrating computer technology and artificial intelligence technology so as to improve students' learning interest and alleviate teachers' teaching pressure [2].

Artificial intelligence technology is a technology that studies how to let the computer complete the intelligent work that originally only human can complete. As one 
of the most advanced information technologies in the world [3], artificial intelligence technology has made many breakthroughs in a number of fields like speech recognition, automation control, corporate management and teaching system. Under this background, this paper focuses on the application of artificial intelligence in college students' autonomous learning [4]. It introduces the implicit knowledge base based on artificial neural network, describes the neural network model and the neural network algorithm process, uses the forgetting curve to establish a knowledge forgetting mathematical model [5], and finally carries out programming design of the English autonomous learning system with Visual Studio computer programming technology, SQL server database and $\mathrm{B} / \mathrm{S}$ system architecture. Through detailed analysis of system requirements, overall structure, database requirements and system flows, this paper specifies the functional module settings and each component of the system [6]. Finally, it displays the interfaces of the artificial-intelligence-based English autonomous learning system, showing that the system provides students with multiple functions like self-diagnosis, online learning and historical exercise. This system has a positive effect in improving the English level of college students and at the same time opens up a new way for the application of artificial intelligence in English teaching.

\section{Overview of Artificial Intelligence and Artificial Neural Network Model}

\subsection{Overview of artificial intelligence}

Artificial intelligence is a new discipline, the main objective of which is to make the computer performance more comprehensive and implant human's intelligent associative thinking model in the computer to make it more intelligent [7].

Development of artificial intelligence: In terms of implementation, the development of artificial intelligence can be divided into three stages:

- Solving problems and completing some logical reasoning work for human, like automated theorem proving, checker playing program and general problem solution in the 1950s and the MYCI disease diagnosis and treatment system during 1972 1976.

- Studying intelligent systems. Intelligent systems can achieve harmony with the environment. With the development of the fifth-generation computer, artificial intelligence was mainly applied in the field of intelligent computer [8].

- Developing intelligent systems with human cognition and thinking. With artificial neural network as the representative, artificial intelligence is being applied in more practical fields like artificial speech recognition, automatic control system and online education.

Actual applications of artificial intelligence: At present, the research and application of artificial intelligence mainly focus on pattern recognition, intelligent database, robot and artificial neural network. The actual application fields mainly include 
- Pattern recognition;

- Natural language understanding;

- Automated theorem proving;

- Program automation;

- Intelligent database system;

- Robot;

- Expert system;

- Artificial neural network; and

- Intelligent teaching system.

This paper mainly integrates artificial intelligence into the application of artificial neural network and intelligent teaching system.

\subsection{Artificial neural network model}

Neural-network-based implicit knowledge base: The knowledge of neural network is abstract and implicit knowledge. The knowledge base stores knowledge about network structure and omniscience, which provides information for reasoning and judging through the neural network learning mode.

The knowledge representation is shown in Formula (1):

$$
\text { If }\left(\mathrm{x}_{1}, \mathrm{x}_{2}, \ldots . \mathrm{x}_{\mathrm{n}}\right)^{\mathrm{T}}=(1,0, \ldots, 0)^{\mathrm{T}} \text { Then }\left(\mathrm{y}_{1}, \mathrm{y}_{2}, \ldots . \mathrm{y}_{\mathrm{m}}\right)^{\mathrm{T}}=(0,1, \ldots, 0)^{\mathrm{T}}
$$

where: $\left(\mathrm{x}_{1}, \mathrm{x}_{2}, \ldots, \mathrm{x}_{\mathrm{n}}\right)^{\mathrm{T}}$ stands for the description of the knowledge points converted from some questions in the question bank; $\left(\mathrm{y}_{1}, \mathrm{y}_{2}, \ldots, \mathrm{y}_{\mathrm{m}}\right)^{\mathrm{T}}$ stands for the diagnosed models of knowledge points [9].

According to the systematic knowledge provided by English experts, English language knowledge is divided into 15 knowledge points, based on which, the sample question bank is set up. When the artificial neural network completes model training, students can complete self-test from the question bank.

Neural network training:

- Determination of network structure, the autonomous learning system uses a threelayer network structure, consisting of input layer, hidden layer and output layer. The number of output layers $n=4.4$ is a binary code, standing for the states of $0-15$, representing 15 knowledge points, respectively. or each knowledge point, 10 questions are selected as samples. Each question has two states - binary code 0 means correct and 1 means wrong.

- Determination of training sample size, Under normal circumstances, the larger the sample size is, the more easily the pattern of the training results can be found, but sample size is often restricted by objective conditions, so the accuracy of training will also be affected. According to experience, the number of samples is generally 5-10 times the total number of network connection weights.

- Collection and training of sample sets, some 2016 grade students were selected from a college to take an English test, which included 150 questions. 2,800 sam- 
ples were taken from the test and divided into two groups, with each containing 1400 samples. These two groups are used as the training sample set and test sample set, respectively. The network uses the traditional BP algorithm, i.e. gradient descent method [10]. The main steps are shown in Figure 1:

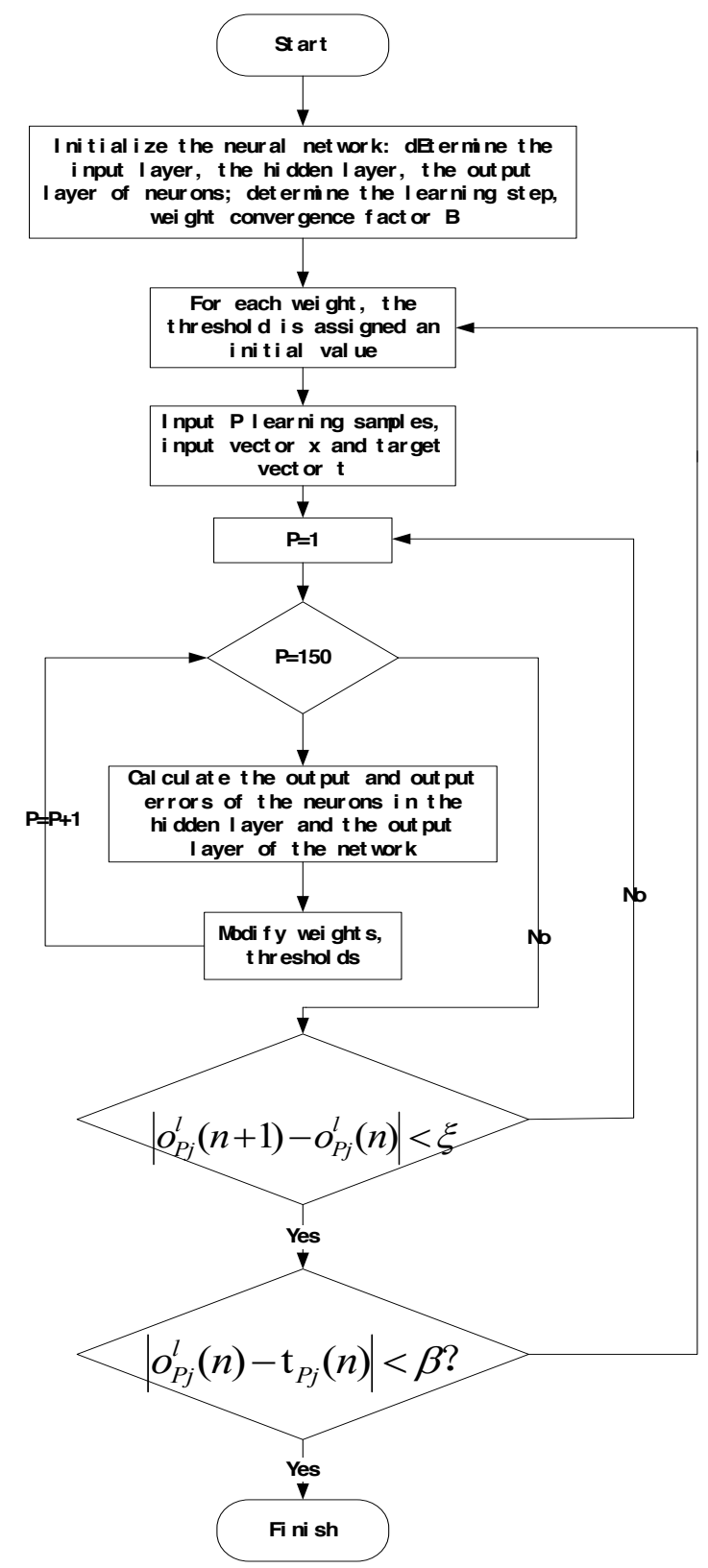

Fig. 1. Flow chart of the BP training algorithm 
Knowledge forgetting mathematical model: Memory is a process of cognizing, storing, recognizing or recalling the past experience while forgetting is the process of not recognizing the past as relevant information cannot be retained or is difficult to extract [11]. Human brain's processing flow of memory and forgetting is shown in Figure 2.

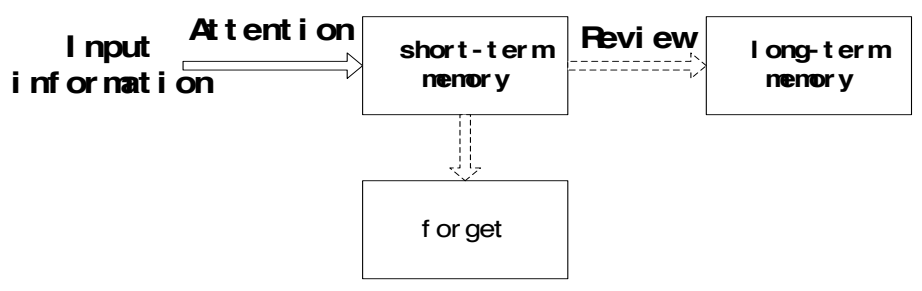

Fig. 2. Memory and forgetting

During English learning, students should improve their information processing efficiency, make full use of short-term memory and organize the information of each memory unit, so that after one practice, the short-term memory can be converted to long-term memory. By paying attention and practicing repeatedly, students will grasp the English knowledge points [12].

The scholar Ebbinghaus, through a large number of researches and experiments, found that the brain has a pattern of forgetting knowledge. In the early stage, the brain forgets very fast and then gradually more slowly. So students must size the time to review English knowledge and it would be better if they can complete the review within one day; otherwise, after one day, their memory will be reduced to about $30 \%$. The English autonomous learning system can provide students with an open review platform, which is of great significance to consolidating English knowledge and improving memory [13].

\section{System Analysis and Design}

\subsection{Overall system design}

The English autonomous learning system based on artificial intelligence focuses on "intelligence", which can make up for the shortage of teachers; it can provide targeted schemes to improve students' weak spots in basic knowledge; in addition, it can improve students' initiatives in autonomous learning and urge students to effectively arrange their learning schedules on a regular basis [14].

System requirement analysis: College English course is difficult but not assigned with many credit hours. What is more, there are a great number of students but only a few teachers. As a result, students find it hard to digest the knowledge they have learnt in class in a timely manner, and teachers cannot instruct every student due to limited energy, not to mention they have to mark students' exercises after class. Therefore, the requirement for the English autonomous learning system, with respect 
to students, is to provide a platform where they can consolidate and review their English knowledge in a timely manner, and with respect to teachers, it is to reduce their heavy workload in marking homework exercises and allow them to play more important guiding roles to help students review [15].

System architecture: The browser/server structure is a three-layer architecture consisting of presentation layer, logic layer and data layer, which accesses the database through the browser. The three-layer architecture is shown in Figure 3.

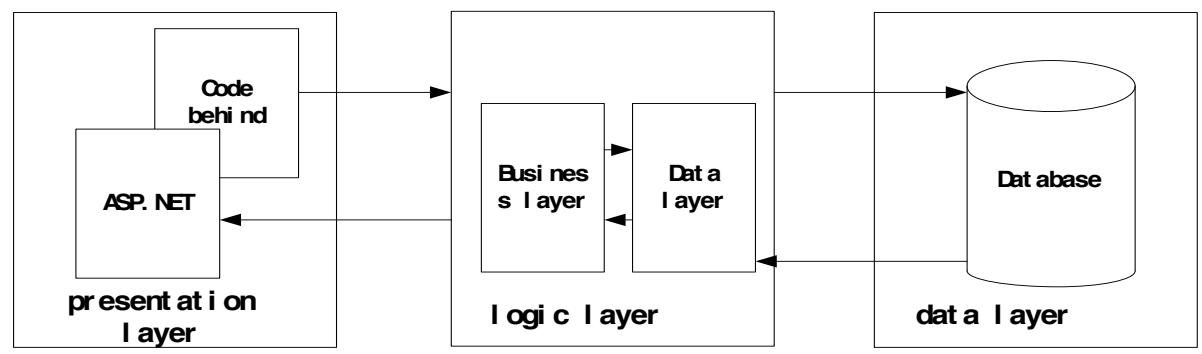

Fig. 3. Three-layer architecture system

The three-layer structure has a strict hierarchical approach. The data access layer can only be accessed by the business logical layer, while the business logic layer can only be accessed by the presentation layer. The user sends the system request through the presentation layer and finally obtains data through the business logic layer and the data access layer.

\subsection{System functional structure analysis}

English autonomous learning system mainly has four types of users: subject matter experts, English teachers, students and system administrator.

The system administrator is mainly responsible for conducting daily maintenance of the system, querying or adding user information of students, English teachers or subject matter experts and also updating and managing the question bank.

Subject matter experts are teachers with many years of experience in English teaching who have a good command of English knowledge points and can provide samples of given formats for neural network training [16].

Teachers refer to ordinary college English teachers, mainly responsible for organizing student examinations, analyzing test results and monitoring how well students grasp the knowledge points.

Students are the main participants in the system. After registration, they will have the authority to use the functions such as exercise, self-diagnosis, historical exercise diagnosis, reinforcement of knowledge points, self-test and test answer query, etc.

The overall system structure is shown in Figure 4. This briefly shows the relationships between different types of users and their main functions. 


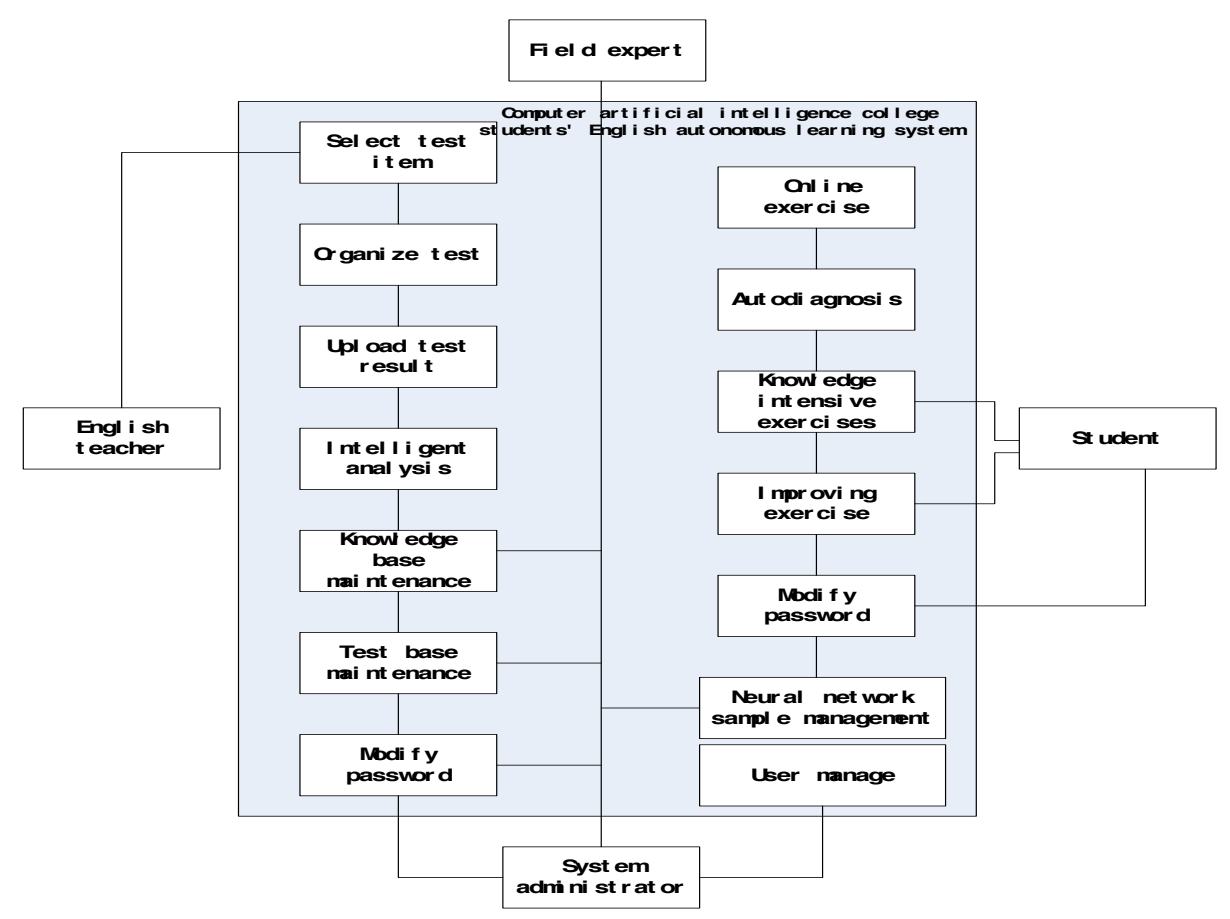

Fig. 4. Overall structure of the system

\subsection{System database design}

The system uses the SQL database, which completes data storage mainly in the form of data tables. There are many types of data tables, including: user information table, static knowledge table, question bank table, knowledge base table, sample management library table, weight management library table and student historical exercise library table.

With the user information table and student exercise table as examples, the storage model of data tables is displayed here. Table 1 is the user basic information table, and Table 2 is the student exercise table.

Table 1. The user basic information table

\begin{tabular}{|l|l|l|}
\hline \multicolumn{1}{|c|}{ Fieldname } & \multicolumn{1}{|c|}{ Data type } & \multicolumn{1}{c|}{ Explanation } \\
\hline Sequence & Int & The user's serial number in the system, incremented \\
\hline UserID & Varchar & The user name, it is unique in the system \\
\hline Password & Varchar & System passw Explanation ord \\
\hline UserType & Int & Whether there are lower knowledge points \\
\hline
\end{tabular}


Table 2. The students practice table

\begin{tabular}{|l|l|l|}
\hline \multicolumn{1}{|c|}{ Fieldname } & Data type & \multicolumn{1}{c|}{ Explanation } \\
\hline StuSequ & Int & Student serial number in student table \\
\hline QuestionSequ & Int & The original serial number in the gallery \\
\hline Flag & Int & Test result right or wrong, 0 that is correct, 1 that error \\
\hline PointSequ & int & Subject to examine the knowledge point serial number \\
\hline Date & datatime & Test time \\
\hline
\end{tabular}

The background configuration for the database is Windows 7, the Web server is the Internet information server (IIS) 6.0, the development software is ASP.NET and the background database is the SQL Server 2003. The database server and the Web server are configured to the same computer for the convenience of development.

\subsection{System processing flow analysis}

A teacher can log in the system, add one exam and organize students to take it according to his/her own teaching content, real-time teaching objectives, students' knowledge level and regular test scores, etc. The examination can be offline or online. The teacher needs to upload the examination results in the form of a document so that system can later evaluate the students by college or class.

The process where students use the autonomous learning system to practice is as follows: first enter the user name and password, and go to the autonomous learning module. In the exercise mode, the system will give individualized assessment and analysis. During the exercise, students can save the record and exit, so that the system can provide the student with the option to continue with the last exercise. Each time after completion of a whole set of exercises, the system will give a basic evaluation to encourage students to practice on their own and enhance their learning interest.

Subject matter experts are mainly responsible for adding knowledge questions, performing detailed analysis of the questions, choices, answers and knowledge points, giving the confirmation degree and making modifications and supplements to the knowledge base.

\section{Implementation of the English Autonomous Learning System for College Students Based on Computer Artificial Intelligence}

After giving the detailed system design, function requirement analysis, system database analysis and data processing flow, this paper implements the programming and testing of the English autonomous learning system for college students.

First of all, the author designs the system login interface, which is mainly used for user system login, password recovery and new user registration. Figure 4 shows the student login interface of the B/S-architecture-based English autonomous learning system. 
After logging in the system, students can operate on the interfaces of the following three parts:

- Self-diagnosis;

- Online learning;

- Historical exercise.

In online learning, students can choose the appropriate knowledge points according to their own situation to take exercises. After completion of the exercise, the system will give feedbacks about the exercise and store them in the database. It will return the analysis results of the exercise to the students and at the same time provide them with data to help them improve their exercise results. Figure 2 shows the system's online exercise interface.

On the historical exercise interface, students can view their exercise records and the detailed exercise results. The learning feedbacks given by the system can help students improve their learning methods and results.

Through testing, it is also confirmed that the functions of teachers and the system administrator satisfy the requirements in the system requirement analysis. The interfaces are omitted here. In summary, through the integration of computer technology and artificial intelligence technology, this paper completes the design and functional implementation of the English autonomous learning system for college students.

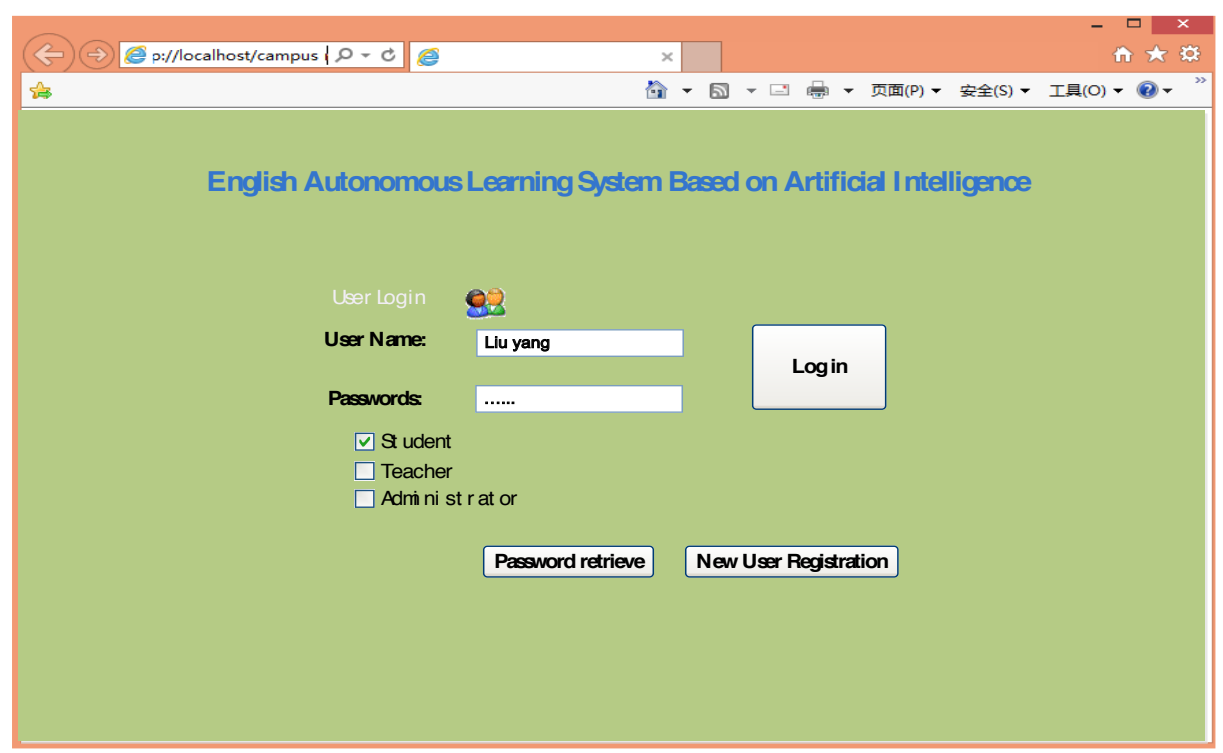

Fig. 5. System login interface for students 


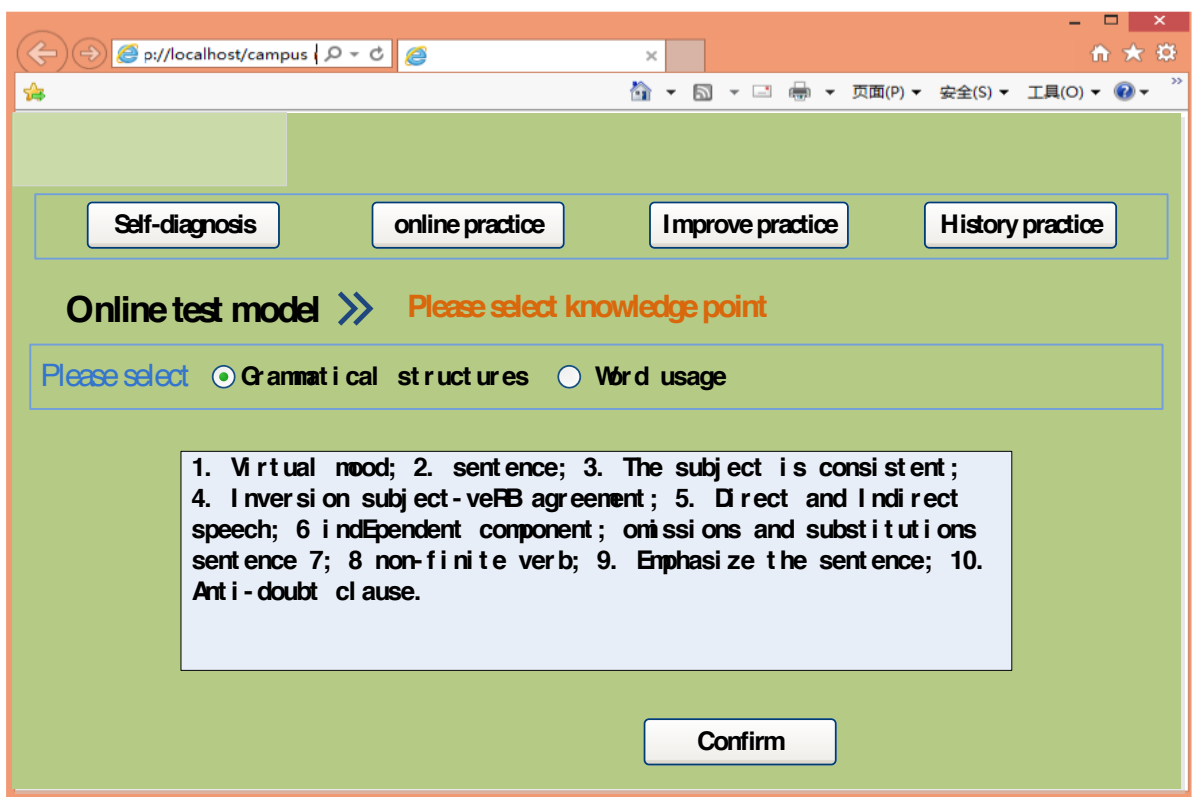

Fig. 6. Online exercise interface

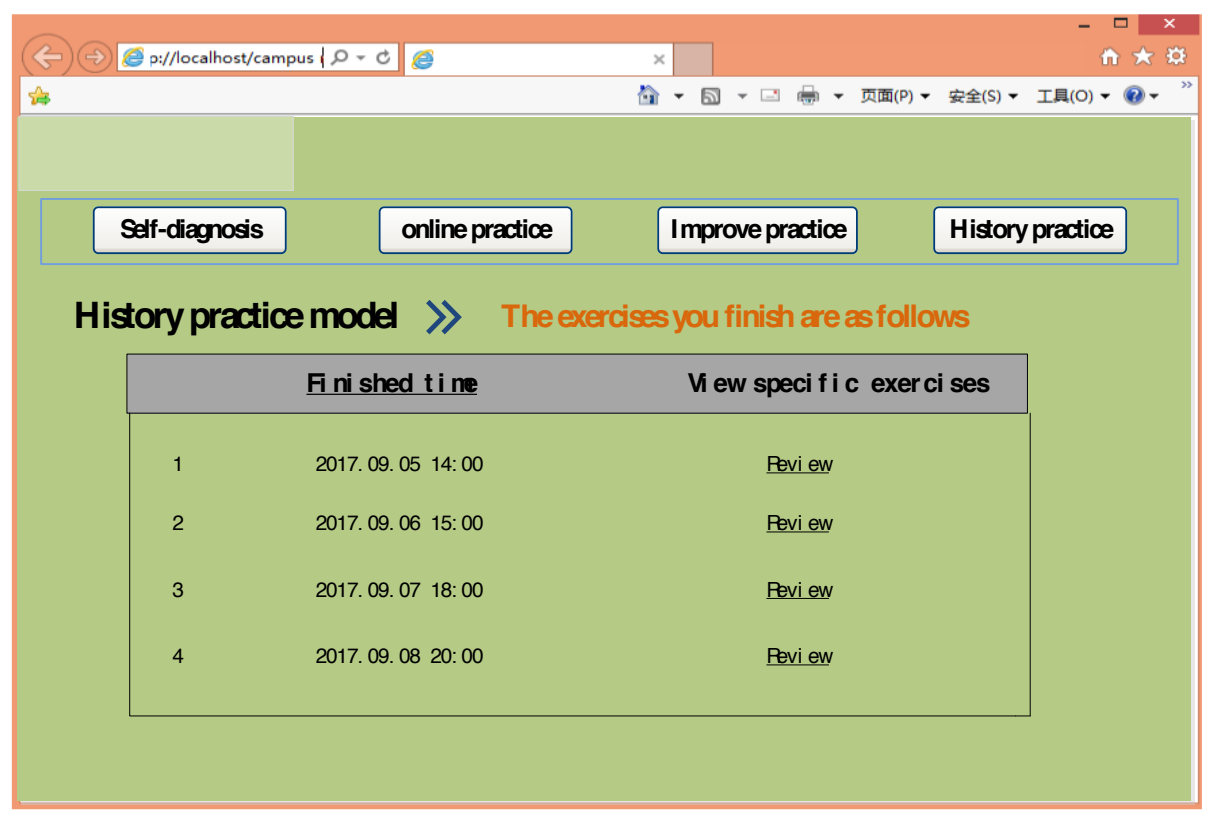

Fig. 7. Historical exercise interface 


\section{Conclusion}

This paper introduces the application of computer artificial intelligence in various fields, explains the implicit knowledge base and training algorithm of BP neural network. By integrating the computer programming technology with artificial intelligence technology, this paper designs and implements the English autonomous learning system for college students based on computer artificial intelligence. This paper has the following conclusions and application significance:

- The system design enables teachers to understand the basic test results of students and have a whole picture of the students' English level in a specific class, college or school.

- The English autonomous learning system designed based on artificial neural network can provide autonomous evaluation on students' exercise and test results.

- The application and promotion of artificial intelligence in English education is of great significance to improving students' initiatives in English learning and reducing teachers' teaching pressure.

\section{References}

[1] Jia, J., \& Zhang, S. (2011). Study on the management model of foreign language teaching reform of higher education. 2011 2nd International Conference on Artificial Intelligence, Management Science and Electronic Commerce (AIMSEC), 28(9), 21-29. http://dx.doi.org/10.1109/AIMSEC.2011.6009850

[2] Tilford, S., Clifton, J., Brice, L., Wiggins-Smith, J., Penrose, L., \& Farooqi, N. (2013). Influence of sex education on condom knowledge and use proficiency among texas college students. Contraception, 88(3), 473-473.

https://doi.org/10.1016/j.contraception.2013.05.160

[3] Yang J.J., Yuan Y.L., Zhang X., Shao L.F., Gong L.H., Mi J., Xu T. (2018). A deep learning-based image recognition algorithm for fecal shape of domestic rabbits, Revue d'Intelligence Artificielle, 32(S1), 67-78. https://doi.org/10.3166/RIA.32.S1.67-78

[4] Yao, X., \& Liu, Y. (2002). A new evolutionary system for evolving artificial neural networks. IEEE Transactions on Neural Networks, 8(3), 694-713. https://doi.org/10.1109/72.572107

[5] Yuan B., Wang F.S., Bao D. (2018). Design and application of a wavelet neural network program for evaluation of goodwill value in corporate intellectual capital, Ingénierie des Systèmes d'Information, 23(5), 185-200. https://doi.org/10.3166/ISI.23.5.185-200

[6] Cao, Y., Yang, L., \& Yang, Y. (2013). Three-Layer EPR Management System Architecture and Development Based on B/S Mode. International Symposium on Information Science and Engineering, 8330, 208-211. http://dx.doi.org/10.1109/ISISE.2012.52

[7] Khokhar, S., Zin, A. A. B. M., Mokhtar, A. S. B., \& Pesaran, M. (2015). A comprehensive overview on signal processing and artificial intelligence techniques applications in classification of power quality disturbances. Renewable \& Sustainable Energy Reviews, 51(November 2015), 1650-1663. https://doi.org/10.1016/j.rser.2015.07.068

[8] Mostefa T., Tarak B., Hachemi G. (2018). An automatic diagnosis method for an open switch fault in unified power quality conditioner based on artificial neural network, Traitement du Signal, 35(1), 7-21. https://doi.org/10.3166/TS.35.7-21 
[9] Huang, M. J., Tsou, Y. L., \& Lee, S. C. (2006). Integrating fuzzy data mining and fuzzy artificial neural networks for discovering implicit knowledge. Knowledge-Based Systems, 19(6), 396-403. https://doi.org/10.1016/j.knosys.2006.04.003

[10] Garai D., Agrawal H., Mishra A.K., Kumar S. (2018). Influence of initiation system on blast-induced ground vibration using random forest algorithm, artificial neural network, and scaled distance analysis, Mathematical Modelling of Engineering Problems, 5(4), 418426. https://doi.org/10.18280/mmep.050419

[11] Rubaai, A., \& Kankam, M. D. (2011). Adaptive tracking controller for induction motor drives using online training of neural networks. IEEE Transactions on Industry Applications, 36(5), 1285-1294. http://dx.doi.org/10.1109/28.871276

[12] Ans, B., \& Rousset, S. (2000). Neural networks with a self-refreshing memory: knowledge transfer in sequential learning tasks without catastrophic forgetting. Connection Science, 12(1), 1-19. https://doi.org/10.1080/095400900116177

[13] Hu, S. G., Liu, Y., Chen, T. P., Liu, Z., Yu, Q., \& Deng, L. J., et al. (2013). Emulating the ebbinghaus forgetting curve of the human brain with a nio-based memristor. Applied Physics Letters, 103(13), 734. https://doi.org/10.1063/1.4822124

[14] Weng, J., Mcclelland, J., Pentland, A., Sporns, O., Stockman, I., Sur, M., \& Thelen, E. (2001). Artificial intelligence. Autonomous mental development by robots and animals. Science, 291(5504), 599-600. https://doi.org/10.1126/science.291.5504.599

[15] Luo, Y. (2010). Probing into autonomous learning in college English instruction. 2010 International Conference on Educational and Information Technology. http://dx.doi.org/10.1109/ICEIT.2010.5607673

[16] Mostefa T., Tarak B., Hachemi G. (2018). An automatic diagnosis method for an open switch fault in unified power quality conditioner based on artificial neural network, Traitement du Signal, 35(1), 7-21. http://dx.doi.org/10.3166/TS.35.7-21

\section{Author}

Bing Han, Female, Hebi Polytechnic, Hebi 458030, China, Master of Science, Her research interests are focused on English Education, E-mail: zibing_water@163.com

Article submitted 2019-01-15. Resubmitted 2019-02-24. Final acceptance 2019-02-26. Final version published as submitted by the authors. 